\title{
Spacecraft Attitude Control
}

\author{
Thawar Arif \\ Applied Science University \\ Jordan
}

\section{Introduction}

The motion of a spacecraft is specified by its position, velocity, attitude, and attitude motion. The first two quantities describe the translational motion of the center of mass of the spacecraft and are the subject of what is called Orbit Determination. The latter two quantities describe the rotational motion of the body of the spacecraft about the center of mass and are the subject of what is called Attitude Determination and Control.

The attitude of a spacecraft is its orientation in space with respect to a defined frame of reference. This chapter ${ }^{1}$ discusses the aspects of spacecraft attitude control. It is an engineering discipline aiming at keeping the spacecraft pointing in the right direction.

In this work, the attitude control of flexible spacecraft is studied. The flexible satellite is considered as a large scale system since it comprises several coupled subsystems. The control of large-scale systems, which are composed of interconnected subsystems, usually goes hand in hand with poor knowledge of the subsystem parameters. As a result, the use of adaptive schemes is particularly appropriate in such a situation. Even assuming perfect parameter knowledge, the design and implementation of a single centralized controller for a large scale system turns out to be a formidable task from the point of view of design complexity as well as associated expenditure (Datta, 1993). Consequently, decentralized adaptive control schemes, whereby each subsystem is controlled independently on the basis of its own local performance criterion and locally available information, have been proposed in the literature (Lyou, 1995; Spooner \& Passino, 1996). The advantages of the decentralized schemes are (Benchoubane \& Stoten, 1992):

1. The controller equations are structurally simpler than the centralized equivalent.

2. No communication is necessary between the individual controllers.

3. Parallel implementations are possible. One of the main advantages to the practical control engineer would be that as the system is expanded, new controller loops could be implemented with no changes to those already in existence. One of the powerful decentralized adaptive control schemes is that developed by (Benchoubane \& Stoten, 1992) called the Decentralized Minimal Controller Synthesis which is an extension of the Minimal Controller Synthesis scheme developed earlier by (Benchoubane \& Stoten, 1990a). The minimal controller synthesis strategy is based on a model reference

\footnotetext{
1 This chapter received support towards its publication from the Deanship of Research and Graduate Studies at Applied Science University, Amman, Jordan. 
adaptive control scheme using positivity and hyperstability concepts in its design procedure to ensure asymptotic stability. The minimal controller synthesis algorithm requires a minimal amount of computation. Various theoretical and experimental studies have shown that it possesses the stability and robustness features essential to any successful adaptive control scheme.

To date, most of the minimal controller synthesis implementation studies have been made on controlling robotic systems (Stoten \& Hodgson, 1992), chaos (Di Bernardo \& Stoten, 2006), X-38 crew return vehicle (Campbell \& Lieven, 2002), or substructuring of dynamical systems (Wagg \& Stoten, 2001).

The Decentralized Minimal Controller Synthesis is adopted in this work for controlling the attitude of flexible spacecraft. Equations of motion are written with respect to a coordinate system fixed in the spacecraft and oriented along its principal axis. The control is by means of three reaction wheels which are also oriented along the principal axes of the spacecraft. It is assumed, for simplicity, that there is no wheel damping and that wheel torque can be controlled precisely.

Many spacecraft attitude control systems, which use Euler angles or direction cosine matrix for parameterization of the attitude kinematics, are based on a sequence of rotations about each of the three principal axes separately (Pande \& Ventachalam, 1982). However, the time needed to realize such a reorientation increases by a factor of two or three, compared with one single three axes slew, which is obtained when the quaternion is used for parameterization (Luo et al, 2005). The quaternion is adopted in this work.

\section{Minimal controller synthesis}

The minimal controller synthesis algorithm (Benchoubane \& Stoten, 1990b) is a significant extension to model reference adaptive control (Landau, 1979). In a similar manner to model reference adaptive control, the aim of minimal controller synthesis is to achieve excellent closed-loop control despite the presence of plant parameters variations, external disturbances, dynamic coupling within the plant and plant non-linearities. However, unlike model reference adaptive control, minimal controller synthesis requires no plant model identification (apart from the general structure of a state space equation) or linear controller synthesis.

Considering a single-input single-output plant described by the following state-space equation:

$$
\dot{\mathbf{x}}_{\mathrm{p}}(\mathrm{t})=\mathrm{Ax}_{\mathrm{p}}(\mathrm{t})+\mathrm{bu}_{\mathrm{p}}(\mathrm{t})+\mathrm{d}(\mathrm{t})
$$

where $\mathbf{x}_{\mathrm{p}}$ is an $\mathrm{n}$-vector, $\mathrm{u}_{\mathrm{p}}$ is a control signal, $\mathbf{A}$ is an $\mathrm{nxn}$ plant coefficient matrix, and $\mathbf{b}$ is an $n \times 1$ control coefficient vector. The term $\mathbf{d}(\mathrm{t})$ represents an $\mathrm{nx} 1$ vector aggregate of unknown external disturbances applied to the plant, plant non-linearities, and any unmodelled terms.

In general, $\mathbf{d}(\mathrm{t}) \neq \mathbf{0}_{\mathrm{n}, 1}$, and if $\mathbf{x}_{\mathrm{p}}(\mathrm{t}) \neq \mathbf{0}_{\mathrm{n}, 1}$, then $\mathbf{d}(\mathrm{t})$ can be represented as (Benchoubane \& Stoten, 1990a):

$$
\mathbf{d}(\mathrm{t})=\delta \mathbf{A}_{1}(\mathrm{t}) \mathbf{x}_{\mathrm{p}}(\mathrm{t})
$$

The term $\delta \mathbf{A}_{1}$ can be considered as an unknown variation in the $\mathbf{A}$ matrix, structured according to any admissible variations in A. Also some other admissible variations in 
matrices $\{\mathbf{A}, \mathbf{b}\}$ can occur, owing to system parameter and/or environmental changes. Let these changes be denoted by $\delta \mathbf{A}_{2}(t)$ and $\delta \mathbf{b}(t)$, respectively; also let:

$$
\delta \mathbf{A}(\mathrm{t})=\delta \mathbf{A}_{1}(\mathrm{t})+\delta \mathbf{A}_{2}(\mathrm{t})
$$

Then the state equation (1) can be rewritten as:

$$
\dot{\mathbf{x}}_{\mathrm{p}}(\mathrm{t})=(\mathbf{A}+\delta \mathbf{A}(\mathrm{t})) \mathbf{x}_{\mathrm{p}}(\mathrm{t})+(\mathbf{b}+\delta \mathbf{b}(\mathrm{t})) \mathrm{u}_{\mathrm{p}}(\mathrm{t})
$$

In common with model reference adaptive control, the objective of the minimal controller synthesis is to ensure that the system state $\mathbf{x}_{\mathrm{p}}(\mathrm{t})$ faithfully follows the state of a reference model despite the effects of the unknown variations $\delta \mathbf{A}(t)$ and $\delta \mathbf{b}(t)$. The reference model is known exactly as (Benchoubane \& Stoten, 1992):

$$
\dot{\mathbf{x}}_{\mathrm{m}}(\mathrm{t})=\mathbf{A}_{\mathrm{m}} \mathbf{x}_{\mathrm{m}}(\mathrm{t})+\mathbf{b}_{\mathrm{m}} \mathrm{u}_{\mathrm{m}}(\mathrm{t})
$$

Where $\mathbf{x}_{m}(t)$ is an $n \times 1$ model reference state vector, $u_{m}(t)$ is a reference signal, $\mathbf{A}_{m}$ is an $n \times n$ model reference coefficient matrix with constant elements, and $\mathbf{b}_{\mathrm{m}}$ is an $\mathrm{nx} 1$ reference signal coefficient vector with constant elements. The control law of the model reference adaptive control is given by (Wertz, 1980):

$$
\mathrm{u}_{\mathrm{p}}(\mathrm{t})=\left(-\mathbf{k}_{\mathrm{p}}+\delta \mathbf{k}_{\mathrm{p}}(\mathrm{t})\right) \mathbf{x}_{\mathrm{p}}(\mathrm{t})+\left(\mathrm{k}_{\mathrm{u}}+\delta \mathrm{k}_{\mathrm{u}}(\mathrm{t})\right) \mathrm{u}_{\mathrm{m}}(\mathrm{t})
$$

where $\mathbf{k}_{\mathrm{p}}$ is a $1 \mathrm{xn}$ constant feedback gain vector and $\mathrm{k}_{\mathrm{u}}$ is a constant feedforward gain. The $\delta \mathbf{k}_{\mathrm{p}}$ and $\delta \mathrm{k}_{\mathrm{u}}$ terms are adaptive changes to these gains that usually result from the effects of $\mathbf{d}(t)$ on the state trajectory, $\mathbf{x}_{\mathrm{p}}(\mathrm{t})$. Whilst the control law of the minimal controller synthesis is given by setting $\mathbf{k}_{\mathrm{p}}=\mathbf{0}_{\mathrm{n}, 1}, \mathrm{k}_{\mathrm{u}}=0$, so that (Benchoubane \& Stoten, 1990b):

$$
\mathrm{u}_{\mathrm{p}}(\mathrm{t})=\delta \mathbf{k}_{\mathrm{p}}(\mathrm{t}) \mathbf{x}_{\mathrm{p}}(\mathrm{t})+\delta \mathrm{k}_{\mathrm{u}}(\mathrm{t}) \mathrm{u}_{\mathrm{m}}(\mathrm{t})
$$

In equation (5), the linear model reference controller gains $\mathbf{k}_{\mathrm{p}}$ and $\mathrm{k}_{\mathrm{u}}$ can be found in closed form, assuming that Erzberger's conditions are satisfied (Isermann, 1992). The satisfaction of Erzberger's conditions tends to restrict the choice of reference model. In particular, equation (6) contravenes the conditions whilst retaining robustness.

Substituting equation (6) into (3) gives:

$$
\dot{\mathbf{x}}_{\mathrm{p}}(\mathrm{t})=\mathbf{A}_{\mathrm{p}}(\mathrm{t}) \mathbf{x}_{\mathrm{p}}(\mathrm{t})+\mathbf{b}_{\mathrm{p}}(\mathrm{t})\left(\delta \mathbf{k}_{\mathrm{p}}(\mathrm{t}) \mathbf{x}_{\mathrm{p}}(\mathrm{t})+\delta \mathrm{k}_{\mathrm{u}}(\mathrm{t}) \mathrm{u}_{\mathrm{m}}(\mathrm{t})\right)
$$

where $\mathbf{A}_{\mathrm{p}}(\mathrm{t})=\mathbf{A}+\delta \mathbf{A}(\mathrm{t})$ and $\mathbf{b}_{\mathrm{p}}(\mathrm{t})=\mathbf{b}+\delta \mathbf{b}(\mathrm{t})$.

Therefore, the closed-loop plant dynamics becomes:

$$
\dot{\mathbf{x}}_{\mathrm{p}}(\mathrm{t})=\left(\mathbf{A}_{\mathrm{p}}(\mathrm{t})+\mathbf{b}_{\mathrm{p}}(\mathrm{t}) \delta \mathbf{k}_{\mathrm{p}}(\mathrm{t})\right) \mathbf{x}_{\mathrm{p}}(\mathrm{t})+\mathbf{b}_{\mathrm{p}}(\mathrm{t}) \delta \mathrm{k}_{\mathrm{u}}(\mathrm{t}) \mathrm{u}_{\mathrm{m}}(\mathrm{t})
$$

From equations (4) and (8), the error dynamics of the closed loop system are given by:

$$
\dot{\mathbf{x}}_{\mathrm{e}}(\mathrm{t})=\mathbf{A}_{\mathrm{m}} \mathbf{x}_{\mathrm{e}}(\mathrm{t})+\left(\mathbf{A}_{\mathrm{o}}(\mathrm{t})-\mathbf{b}_{\mathrm{p}}(\mathrm{t}) \delta \mathbf{k}_{\mathrm{p}}(\mathrm{t})\right) \mathbf{x}_{\mathrm{p}}(\mathrm{t})+\left(\mathbf{b}_{\mathrm{m}}-\mathbf{b}_{\mathrm{p}}(\mathrm{t}) \delta \mathrm{k}_{\mathrm{u}}(\mathrm{t})\right) \mathrm{u}_{\mathrm{m}}(\mathrm{t})
$$

where $\mathbf{x}_{\mathrm{e}}(\mathrm{t})$ is an $\mathrm{nx} 1$ error state vector which is given by $\mathbf{x}_{\mathrm{e}}(\mathrm{t})=\mathbf{x}_{\mathrm{m}}(\mathrm{t})-\mathbf{x}_{\mathrm{p}}(\mathrm{t})$. While $\mathbf{A}_{\mathrm{o}}(\mathrm{t})=\mathbf{A}_{\mathrm{m}}$ - $A_{p}(t)$.

From equation (9), let:

$$
\mathbf{v}(t)=\left(\mathbf{A}_{\mathrm{o}}(\mathrm{t})-\mathbf{b}_{\mathrm{p}}(\mathrm{t}) \delta \mathbf{k}_{\mathrm{p}}(\mathrm{t})\right) \mathbf{x}_{\mathrm{p}}(\mathrm{t})+\left(\mathbf{b}_{\mathrm{m}}-\mathbf{b}_{\mathrm{p}}(\mathrm{t}) \delta \mathrm{k}_{\mathrm{u}}(\mathrm{t})\right) \mathrm{u}_{\mathrm{m}}(\mathrm{t})
$$


so that:

$$
\dot{\mathbf{x}}_{\mathrm{e}}(\mathrm{t})=\mathbf{A}_{\mathrm{m}} \mathbf{x}_{\mathrm{e}}(\mathrm{t})+\mathbf{I}_{\mathrm{n}} \mathbf{v}(\mathrm{t})
$$

where $\mathbf{I}_{\mathrm{n}}$ is an nxn identity matrix.

The absolute stability of equation (11) is investigated by the application of hyperstability theory and Popov's criterion to the equivalent non-linear closed-loop system (Landau, 1979). In this system, shown in figure (1), let: $\mathbf{v}(\mathrm{t})=-\mathbf{v}_{\mathrm{e}}(\mathrm{t})$ and $\mathbf{v}_{\mathrm{e}}(\mathrm{t})$ is generated by a necessarily non-linear function of the output error vector $\mathbf{y}_{\mathrm{e}}(\mathrm{t})$ (this constitutes the adaptive block); where: $\mathbf{y}_{\mathrm{e}}(\mathrm{t})=\mathbf{P} \mathbf{x}_{\mathrm{e}}(\mathrm{t})$. $\mathbf{P}$ is an $\mathrm{nxn}$ positive definite symmetric matrix which is the solution of the Lyapunov matrix equation:

$$
\mathbf{P A} \mathbf{A}_{\mathrm{m}}+\mathbf{A}_{\mathrm{m}}^{\mathrm{T}} \mathbf{P}=-\mathbf{Q}
$$

where $\mathbf{Q}$ is an $n \times n$ positive definite matrix.

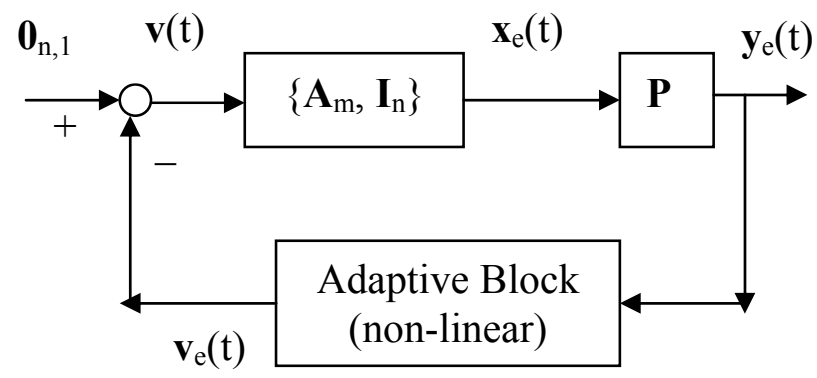

Fig. 1. Closed-Loop System Equivalent to Equations (10) \& (11)

The system (11) is hyperstable if the block $\left\{\mathbf{A}_{\mathrm{m}}, \mathbf{I}_{\mathrm{n}}, \mathbf{P}\right\}$ is a hyperstable block, i.e. satisfies Lyapunov matrix equation (12), and the following Popov's inequality is satisfied (Landau, 1979):

$$
\int_{t_{0}}^{t_{1}} y_{e}^{T}(t) v_{e}(t) d t \geq-\mu^{2}, \quad \mu \geq 0 \text { f for all } t_{1} \geq t_{0}
$$

For a given reference model and arbitrary positive definite matrix $\mathbf{Q}$, the Lyapunov matrix equation (12) can be solved to yield the positive definite symmetric matrix $\mathbf{P}$ (Landau \& Courtiol, 1974). It remains to satisfy equation (13), which can be rewritten, using equation (10), as:

$$
\int_{t 0}^{\pi_{0}^{2}} y_{t}^{T}(t)\left(b_{p}(t) \delta k_{p}(t)=A_{0}(t)\right) x_{p}(t) d t \geq-\mu_{1}^{2}
$$

And

$$
\int_{t_{0}}^{t_{1}} y_{e}^{T}(t)\left(b_{p}(t) \delta k_{u}(t)-b_{m}\right) u_{m}(t) d t \geq-\mu_{2}^{2}
$$


Where

$$
\mu_{1}^{2}+\mu_{2}^{2}=\mu^{2}
$$

The satisfaction of equations (14) is explained in (Arif, 2008).

\section{Decentralized minimal controller synthesis}

It is assumed that the multivariable system to be controlled can be modeled as an interconnection of $(\mathrm{m})$ single-input single-output subsystems, whose individual dynamics are described by:

$$
\mathbf{x}_{\mathrm{pi}}=\mathbf{A}_{\mathrm{pi}} \mathbf{x}_{\mathrm{pi}}+\mathbf{b}_{\mathrm{pi}} \mathrm{u}_{\mathrm{pi}}+\mathbf{d}_{\mathrm{i}}+\sum_{\substack{\mathrm{j}=1 \\ \mathrm{j} \neq \mathrm{i}}}^{\mathrm{m}} \mathbf{f}_{\mathrm{ij}}\left(\mathrm{t}, \mathbf{x}_{\mathrm{pj}}\right)+\sum_{\substack{\mathrm{j}=1 \\ j \neq i}}^{m} \mathbf{b}_{\mathrm{pij}} \mathrm{u}_{\mathrm{pj}} ;(1=1,2, \ldots, \mathrm{m})
$$

where for this $i_{\text {th }}$ subsystem:

$\mathbf{x}_{\mathrm{pi}}$ is the state vector of dimension $\mathrm{n}_{\mathrm{i}}$ defined as:

$$
\mathbf{x}_{\mathrm{pi}}=\left[\begin{array}{llll}
\mathrm{x}_{\mathrm{pi} 1} & \mathrm{x}_{\mathrm{p} \mathrm{2}} & \ldots & \mathrm{x}_{\mathrm{pini}}
\end{array}\right]
$$

$d_{i}$ is the bounded vector of dimension $n_{i}$ containing the subsystem nonlinearities and external disturbances, $u_{\mathrm{pi}}$ is the control variable, $\mathbf{f}_{\mathrm{ij}}\left(\mathrm{t}, \mathbf{x}_{\mathrm{pj}}\right)$ and $\mathbf{b}_{\mathrm{pij}} \mathrm{u}_{\mathrm{pj}}$ are vectors of dimension $\mathrm{n}_{\mathrm{i}}$ representing the bounded interactions with the other subsystem states and control.

Further, the matrix $\mathbf{A}_{\mathrm{pi}}$ and the vector $\mathbf{d}_{\mathrm{i}}$ have unknown parameters, but with the assumed structures:

$$
\begin{gathered}
\mathbf{A}_{\mathrm{pi}}=\left[\begin{array}{ccccc}
0 & 1 & 0 & \cdots & 0 \\
0 & 0 & 1 & \cdots & 0 \\
\vdots & \vdots & \vdots & \vdots & \vdots \\
0 & 0 & 0 & \cdots & 1 \\
-\mathrm{a}_{\mathrm{pi} 1} & -\mathrm{a}_{\mathrm{pi} 2} & -\mathrm{a}_{\mathrm{pi} 3} & \cdots & -\mathrm{a}_{\mathrm{pini}}
\end{array}\right] \\
\mathbf{b}_{\mathrm{pi}}=\left[\begin{array}{c}
0 \\
0 \\
\vdots \\
0 \\
\mathrm{~b}_{\mathrm{pini}}
\end{array}\right] \\
\mathbf{b}_{\mathrm{pij}}
\end{gathered}
$$




$$
\mathbf{d}_{\mathrm{i}}=\left[\begin{array}{c}
0 \\
0 \\
\vdots \\
0 \\
\mathrm{~d}_{\mathrm{ini}}
\end{array}\right]
$$

The state interaction terms $\mathbf{f}_{\mathrm{ij}}\left(\mathrm{t}, \mathbf{x}_{\mathrm{pj}}\right)$ are of the form:

which satisfy the inequality:

$$
\mathbf{f}_{\mathrm{ij}}\left(\mathrm{t}, \mathbf{x}_{\mathrm{pj}}\right)=\left[\begin{array}{llll}
0 & \ldots & 0 & \mathbf{f}_{\mathrm{ij}}
\end{array}\right]^{\mathrm{T}}
$$

$$
|| \mathbf{f}_{i j}\left(t, x_{p j}\right)|| \leq c_{i j}|| \mathbf{x}_{p j}||
$$

where $\mathrm{c}_{\mathrm{ij}}$ are finite positive, unknown, coefficients.

The system dynamics in a full multivariable guise can be written as:

$$
\dot{\mathbf{x}}_{\mathrm{p}}(\mathrm{t})=\mathbf{A}_{\mathrm{p}} \mathbf{x}_{\mathrm{p}}(\mathrm{t})+\mathbf{b}_{\mathrm{p}} \mathrm{u}_{\mathrm{p}}(\mathrm{t})+\mathrm{d}(\mathrm{t})+\mathbf{f}\left(\mathrm{t}, \mathbf{x}_{\mathrm{p}}\right)
$$

where

$$
\begin{gathered}
\mathbf{x}_{\mathrm{p}}(\mathrm{t})=\left[\begin{array}{llll}
\mathbf{x}_{\mathrm{p} 1}^{\mathrm{T}} & \mathbf{x}_{\mathrm{p} 2}^{\mathrm{T}} & \ldots & \mathbf{x}_{\mathrm{pm}}^{\mathrm{T}}
\end{array}\right]^{\mathrm{T}=\text { the complete state vector. }} \\
\mathrm{u}_{\mathrm{p}}(\mathrm{t})=\left[\begin{array}{llll}
\mathrm{u}_{\mathrm{p} 1} & \mathrm{u}_{\mathrm{p} 2} & \ldots & \mathrm{u}_{\mathrm{pm}}
\end{array}\right]^{\mathrm{T}=\text { the complete control vector. }} \\
\mathbf{d}(\mathrm{t})=\left[\begin{array}{lll}
\mathbf{d}_{1}^{\mathrm{T}} \mathbf{d}_{2}^{\mathrm{T}} & \ldots & \mathrm{d}_{\mathrm{m}}^{\mathrm{T}}
\end{array}\right]^{\mathrm{T}=} \text { the complete disturbance/nonlinearities vector. } \\
\mathbf{f}\left(\mathrm{t}, \mathbf{x}_{\mathrm{p}}\right)=\left[\begin{array}{l}
\left.\mathbf{f}_{\mathrm{ij}}\left(\mathrm{t}, \mathbf{x}_{\mathrm{pj}}\right)\right] \text { if } \mathrm{i} \neq \mathrm{j} \\
\mathbf{f}\left(\mathrm{t}, \mathbf{x}_{\mathrm{p}}\right)=[0] \text { if } \mathrm{i}=\mathbf{j}
\end{array}\right.
\end{gathered}
$$

and

$$
\begin{gathered}
\mathbf{A}_{\mathrm{p}}=\operatorname{diag}\left[\mathbf{A}_{\mathrm{pi}}\right] \\
\mathbf{b}_{\mathrm{p}}=\left[\mathbf{b}_{\mathrm{pij}}\right] ; \text { where } \mathbf{b}_{\mathrm{pii}}=\mathbf{b}_{\mathrm{pi}}
\end{gathered}
$$

the objective of decentralized minimal controller synthesis is to drive the control signal $u_{\mathrm{pi}}$ for each subsystem given by equation (15), using local information, so that the corresponding states track those of a local reference model, described by:

$$
\dot{\mathbf{x}}_{\mathrm{mi}}(\mathrm{t})=\mathbf{A}_{\mathrm{mi}} \mathbf{x}_{\mathrm{mi}}+\mathbf{b}_{\mathrm{mi}} \mathrm{u}_{\mathrm{mi}}
$$

where $\mathbf{x}_{\mathrm{mi}}$ is the $i_{\text {th }}$ reference model state vector of dimension $n_{i}$ and $u_{m i}$ is the bounded reference input. Furthermore, the matrix $\mathbf{A}_{\mathrm{mi}}$ and the vector $\mathbf{b}_{\mathrm{mi}}$ are defined as:

$$
\mathbf{A}_{\mathrm{mi}}=\left[\begin{array}{ccccc}
0 & 1 & 0 & \cdots & 0 \\
0 & 0 & 1 & \cdots & 0 \\
\vdots & \vdots & \vdots & \vdots & \vdots \\
0 & 0 & 0 & \cdots & 1 \\
-\mathrm{a}_{\mathrm{mi}} & -\mathrm{a}_{\mathrm{mi} 2} & -\mathrm{a}_{\mathrm{mi}} & \cdots & -\mathrm{a}_{\mathrm{mini}}
\end{array}\right]
$$




$$
\mathbf{b}_{\mathrm{mi}}=\left[\begin{array}{c}
0 \\
0 \\
\vdots \\
0 \\
\mathrm{~b}_{\operatorname{mini}}
\end{array}\right]
$$

Therefore, the local information available to the $i_{\text {th }}$ subsystem is the set of variables $\left\{\mathbf{x}_{\mathrm{mi}}, \mathbf{x}_{\mathrm{p} i}\right.$ $\left.\mathrm{u}_{\mathrm{mi}}\right\}$. The error vector $\mathbf{x}_{\mathrm{ei}}$ corresponding to the $\mathrm{i}_{\mathrm{th}}$ subsystem is:

$$
\mathbf{x}_{\mathrm{ei}}=\mathbf{x}_{\mathrm{mi}}-\mathbf{x}_{\mathrm{pi}}
$$

and by using equations (15) and (20) we get:

$$
\hat{\mathbf{x}}_{\mathrm{ei}}=\boldsymbol{A}_{\mathrm{mi}} \mathbf{x}_{\mathrm{ei}}-\mathbf{b}_{\mathrm{pi}} \mathrm{u}_{\mathrm{pi}}-\left(\boldsymbol{A}_{\mathrm{pi}}-\mathbf{A}_{\mathrm{mi}}\right) \mathbf{x}_{\mathrm{pi}}+\mathbf{b}_{\mathrm{mi}} \mathrm{u}_{\mathrm{mi}}-\mathbf{d}_{\mathrm{i}}-\sum_{\substack{\mathrm{j}=1 \\ j \neq i}}^{m} \mathbf{f}_{\mathrm{ij}}\left(\mathrm{t}, \mathbf{x}_{\mathrm{pj}}\right)-\sum_{\substack{\mathrm{j}=1 \\ j \neq i}}^{m} \mathbf{b}_{\mathrm{ij}} \mathrm{u}_{\mathrm{pj}}
$$

Or

$$
\dot{\mathbf{x}}_{\mathrm{ei}}(\mathrm{t})=\mathbf{A}_{\mathrm{mi}} \mathbf{x}_{\mathrm{ei}}-\lambda_{\mathrm{i} 1}-\lambda_{\mathrm{i} 2}
$$

where

$$
\begin{gathered}
\lambda_{\mathrm{i} 1}=\mathbf{b}_{\mathrm{pi}} \mathrm{u}_{\mathrm{pi}}+\left(\mathbf{A}_{\mathrm{pi}}-\mathbf{A}_{\mathrm{mi}}\right) \mathbf{x}_{\mathrm{pi}}-\mathbf{b}_{\mathrm{mi}} \mathrm{u}_{\mathrm{mi}} \\
\boldsymbol{\lambda}_{\mathrm{i} 2}=\mathbf{d}_{\mathrm{i}}+\sum_{\substack{j=1 \\
j \neq i}}^{\mathrm{m}} \mathbf{f}_{\mathrm{ij}}\left(\mathrm{t}, \mathbf{x}_{\mathrm{pj}}\right)+\sum_{\substack{\mathrm{j}=1 \\
\mathrm{j} \neq \mathrm{i}}}^{\mathrm{m}} \mathbf{b}_{\mathrm{pij}} \mathrm{u}_{\mathrm{pj}}
\end{gathered}
$$

Following the form of the minimal controller synthesis; the control law (6) is proposed for each subsystem, as follows:

$$
\mathrm{u}_{\mathrm{pi}}=\delta \mathbf{k}_{\mathrm{pi}} \mathbf{x}_{\mathrm{pi}}+\delta \mathrm{k}_{\mathrm{ui}} \mathrm{u}_{\mathrm{mi}}
$$

where

$$
\begin{aligned}
& \delta \mathbf{k}_{\mathrm{pi}}=\int_{Q}^{\mathrm{t}} \alpha_{\mathrm{i}} \mathrm{y}_{\mathrm{ni}} \mathbf{x}_{\mathrm{pi}}^{\mathrm{T}} \mathrm{d} \tau+\beta_{\mathrm{i}} \mathrm{y}_{\mathrm{ni}} \mathbf{x}_{\mathrm{pi}}^{T} \\
& \delta k_{v i}=\int_{0}^{t} \alpha_{i} y_{n i} u_{m i} d \tau+\beta_{i} y_{n i} u_{m i} \\
& \mathrm{y}_{n i}=\Gamma_{\mathrm{i}}^{\mathrm{T}} \mathbf{P}_{\mathrm{i}} \mathbf{x}_{\mathrm{ei}} \\
& \Gamma_{\mathrm{i}}=\left[\begin{array}{llll}
0 & \ldots & 0 & 1
\end{array}\right]^{\mathrm{T}}=\left(\mathrm{n}_{\mathrm{i}} \times 1\right) \text { vector }
\end{aligned}
$$


$\mathbf{P}_{\mathbf{i}}$ is the symmetric positive definite solution of the following Lyapunov equation:

$$
\mathbf{P}_{\mathrm{i}} \mathbf{A}_{\mathrm{mi}}+\mathbf{A}_{\mathrm{mi}}^{\mathrm{T}} \mathbf{P}_{\mathrm{i}}=-\mathbf{Q}_{\mathrm{i}}
$$

where $\mathbf{Q}_{\mathrm{i}}=\operatorname{diag}\left(\mathrm{q}_{11} \mathrm{q}_{22}\right)$ is a positive definite matrix. The elements of $\mathbf{Q}$ are to be selected by the designer. $\alpha_{i}$ and $\beta_{i}$ are constant gains.

For a given reference model and arbitrary positive definite matrix $\mathbf{Q}$, the Lyapunov matrix equation (30) can be solved to yield the positive definite symmetric matrix $\mathbf{P}$ (Landau \& Courtiol, 1974).

With the aid of equations (25) to (29) the error dynamics given by equation (23) can be rewritten as follows:

$$
\dot{\mathbf{x}}_{\mathrm{ei}}=\mathbf{A}_{\mathrm{mi}} \mathbf{x}_{\mathrm{ei}}-\Gamma_{\mathrm{i}} \Phi_{\mathrm{i}}^{\mathrm{T}} \mathbf{Z}_{\mathrm{i}}-\Gamma_{\mathrm{i}} \Psi_{\mathrm{i}}^{\mathrm{T}} \mathbf{Z}_{\mathrm{i}}-\lambda_{\mathrm{i} 2}
$$

where

$$
\begin{aligned}
& \Phi_{i}^{T}=\left[b_{\text {pini }} \int_{Q}^{t} x_{i} y_{\text {ni }} x_{\text {pi1 }} d \tau-\left(a_{\text {mi1 }}-a_{\text {pi1 }}\right), \ldots, b_{\text {pini }} \int_{Q}^{t} x_{i} y_{n i} x_{\text {pini }} d \tau\right. \\
& \left.-\left(a_{\text {mini }}-a_{\text {pini }}\right), b_{\text {pini }} \int_{g}^{t} \alpha_{i} y_{n i} u_{m i} d \tau-b_{\text {mini }}\right] \\
& \mathbf{Z}_{\mathrm{i}}=\left[\begin{array}{ll}
\mathbf{x}_{\mathrm{pi}}^{\mathrm{T}} & \mathrm{u}_{\mathrm{mi}}
\end{array}\right]^{\mathrm{T}} \\
& \Psi_{\mathrm{i}}=\mathrm{b}_{\text {pini }} \beta_{\mathrm{i}} \mathrm{y}_{\mathrm{ni}} \mathbf{Z}_{\mathrm{i}}
\end{aligned}
$$

\subsection{Stability and robustness of decentralized minimal controller synthesis algorithm}

Equations (31) to (34) define the closed-loop dynamics of the system described by equation (15), under the decentralized minimal controller synthesis control strategy described by equations (25) to (30). These closed-loop equations can be guaranteed hyperstable if the parameters in $\lambda_{\mathrm{i} 2}$ (equations (24) and (31)) vary slowly, i.e. compared with the speed of the individual adaptive control loops.

The procedure now follows the approach taken in (Benchoubane \& Stoten, 1992), whereby the approximately constant parameters are incorporated into the corresponding entries of $\Phi_{\mathrm{i}}$. Thus, rewrite $\lambda_{\mathrm{i} 2}$ as:

$$
\lambda_{\mathrm{i} 2}=\delta \mathbf{A}_{\mathrm{pi}} \mathrm{u}_{\mathrm{mi}}
$$

where $\delta \mathbf{A}_{\text {pi }}$ is an unknown $\left(\mathrm{n}_{\mathrm{i}} \times 1\right)$ vector defined as:

$$
\delta \mathbf{A}_{\mathrm{pi}}=\left[\begin{array}{llll}
0 & \ldots & 0 & \delta \mathrm{a}_{\mathrm{pi}}
\end{array}\right]^{\mathrm{T}}
$$

Therefore, the speed of variation of $\delta \mathbf{A}_{\mathrm{pi}}$ is determined by both the speeds of variation of $\mathrm{u}_{\mathrm{mi}}$ and $\lambda_{\mathrm{i} 2}$. However, in many practical situations, the reference inputs are relatively slowly varying, and therefore the speed of variation of $\delta \mathbf{A}_{\mathrm{pi}}$ is only dependent upon $\lambda_{\mathrm{i} 2}$. Thus, if the terms $\boldsymbol{\lambda}_{\mathrm{i} 2}$ is slowly varying, the terms $\delta \mathbf{A}_{\mathrm{pi}}$ can be considered as approximately constant and incorporated into the last entry of each $\boldsymbol{\Phi}_{\mathrm{i}}$ : 


$$
\begin{aligned}
& \boldsymbol{\Phi}_{i}^{T}=\left[b_{\text {pini }} \int_{0}^{t} \alpha_{i} y_{n i} x_{\text {pi2 }} d \tau=\left(a_{\text {mi1 }}-a_{\text {pis }}\right), \ldots, b_{\text {pini }} \int_{0}^{t} \alpha_{i} y_{n i} x_{\text {pini }} d \tau\right. \\
& -\left(a_{\text {mini }}-a_{\text {pini }}\right), b_{\text {pini }} \int_{0}^{t} \alpha_{i} y_{n i} u_{m i} d \tau+\delta_{a_{p i}}-b_{\text {minil }}
\end{aligned}
$$

Now equation (31) may be rewritten as:

$$
\dot{\mathbf{x}}_{\mathrm{ei}}=\mathrm{A}_{\mathrm{mi}} \mathbf{x}_{\mathrm{ei}}-\Gamma_{\mathrm{i}} \Phi_{\mathrm{i}}^{\mathrm{T}} \mathbf{Z}_{\mathrm{i}}-\Gamma_{\mathrm{i}} \Psi_{\mathrm{i}}^{\mathrm{T}} \mathbf{Z}_{\mathrm{i}}
$$

It then follows that equation (38) defines a hyperstable system if (Isermann, 1992):

$$
\begin{aligned}
& \alpha_{\mathrm{i}} \mathrm{b}_{\text {pini }}>0 \\
& \beta_{\mathrm{i}} \mathrm{b}_{\text {pini }} \geq 0
\end{aligned}
$$

and if the system parameter variations are slow compared with the speed of the individual adaptive control loops.

In summary, if the disturbances $\mathbf{d}_{\mathbf{i}}$ and the coupling terms are slowly varying, then the errors are globally asymptotically stable.

\section{Attitude control of flexible spacecraft}

Many spacecrafts have large solar panel arrays with significant structural flexibility. The structural mode interaction with attitude control system has been one of the primary concerns for the design of 3-axis stabilized spacecraft (Wie \& Plescia, 1984).

The main objective of the control system is to control the attitude of the spacecraft, which includes the contributions of both the rigid-body modes and the elastic modes. Considerable volume of literature (Metzger, 1979; Breakwell, 1981; Skaar et al., 1986) on flexible spacecraft focused on controlling only elastic modes, with the premise that control of rigid modes is straightforward and can be dealt with separately. This approach suffers from the fact that rigid modes are coupled with the elastic modes through control inputs and sensor observations, and cannot be separated from the elastic modes for controller design (Joshi et al., 1995).

The very simple flexible spacecraft configuration is shown in figure (2), where

$\mathrm{x}, \mathrm{y}, \mathrm{z}=$ principal axes of inertia of the undeformed spacecraft,

$X, Y, Z=$ axes through the spacecraft center of mass, fixed in space,

$\theta_{\mathrm{x}}, \theta_{\mathrm{y}}, \theta_{\mathrm{z}}=$ Euler angles: pitch, roll, and yaw.

\subsection{Modeling of the flexible spacecraft}

Flexible arrays are modeled as a mass-spring-dashpot system mounted on a rigid massless rod attached to the main body of the spacecraft via a coil spring to simulate torsional effects. The spacecraft and its flexible solar arrays are modeled as a rigid central body with each solar array represented as a point mass with two degrees of freedom, displacements in the roll-yaw plane, and by a disc having torsional rotation only about the pitch array axis (x-axis). The disc is circular spring whose mass is negligible compared with the spacecraft's body mass, as shown in figure (3). $\mathrm{K}_{\mathrm{x}}, \mathrm{K}_{\mathrm{y}}$, and $\mathrm{K}_{\mathrm{z}}$ are the spring constants and $\mathrm{C}_{\mathrm{x}}, \mathrm{C}_{\mathrm{y}}$, and $\mathrm{C}_{\mathrm{z}}$ are the damping factors. The coordinates $a_{y}, a_{z}, \beta_{y}$, and $\beta_{z}$ (deflection) and $a_{x}$ and $\beta_{x}$ (rotation), which describe the position of movable parts with respect to the main body (Van Woerkom, 1985). 


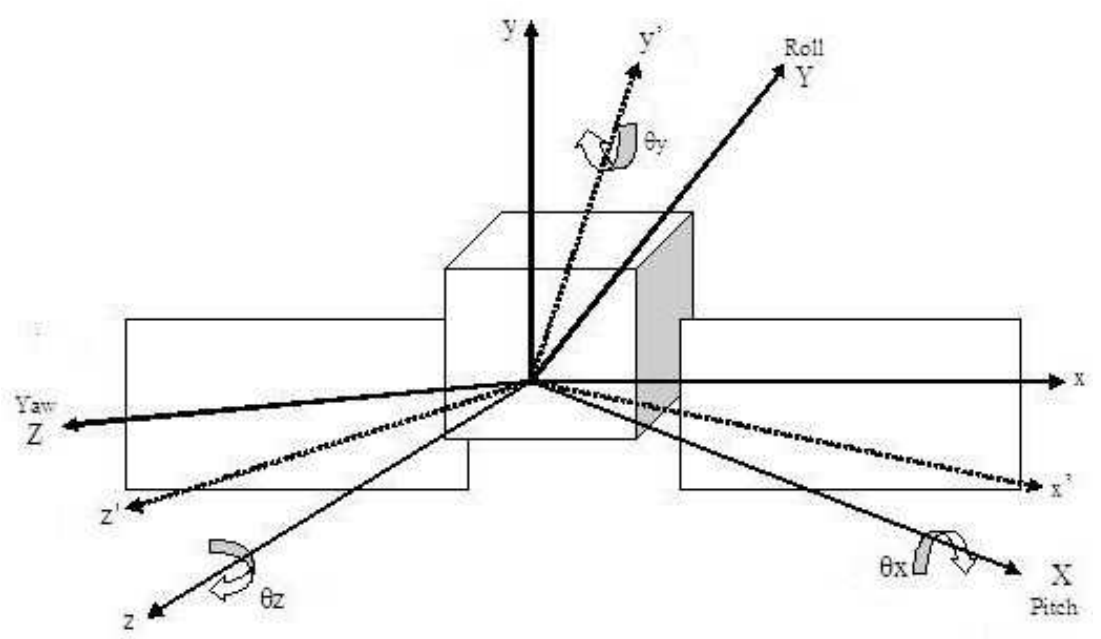

Fig. 2. Configuration of Flexible Spacecraft

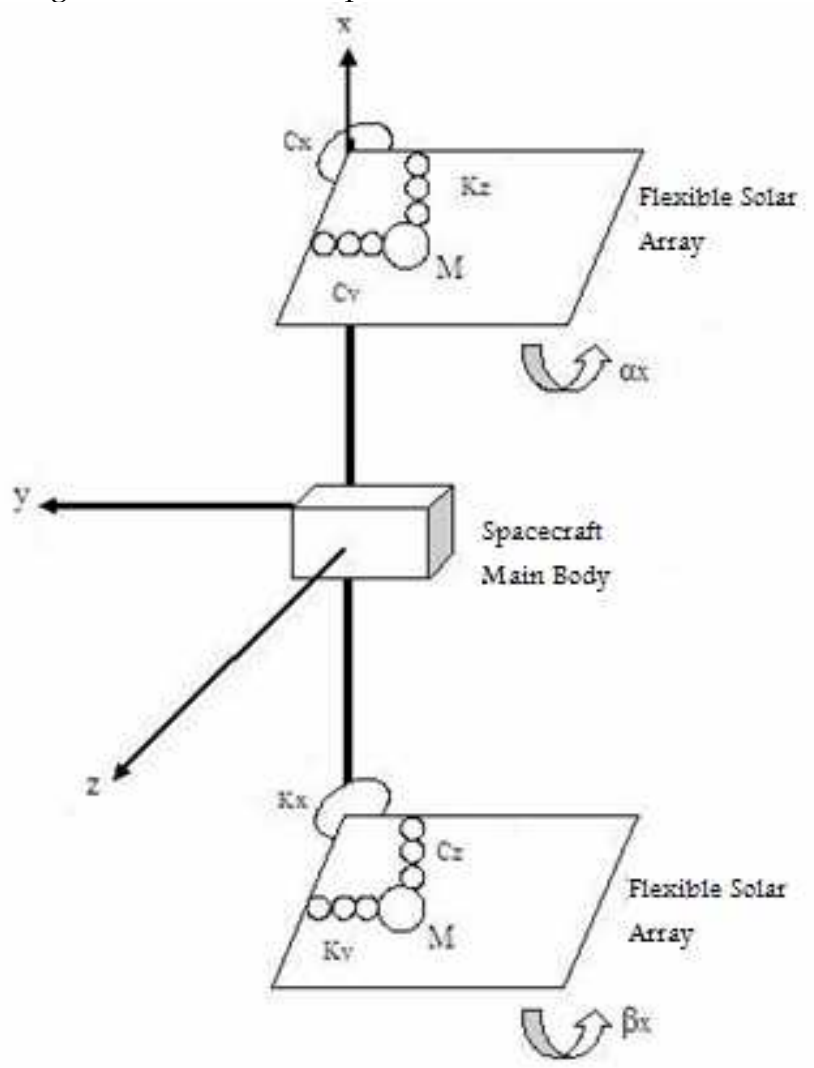

Fig. 3. Dynamic Model of Flexible Spacecraft 
By having:

$\mathrm{M}=$ value of the point mass,

$\mathrm{L}=$ distance of the point mass from the spacecraft center of mass,

$\mathrm{I}_{\mathrm{f}}=$ moment of inertia of the movable material frame with respect to the $\mathrm{x}$-axis,

the moments of inertia of the undeformed spacecraft are:

$$
\begin{gathered}
I_{x x}=I_{x}+2 I_{f} \\
I_{y y}=I_{y}+2 M L^{2} \\
I_{z z}=I_{z}+2 M L^{2}
\end{gathered}
$$

where $I_{x}, I_{y}$, and $I_{z}$ are the principal moments of inertia of the rigid body. Assuming small deflections/rotations of the appendages (i.e. $\alpha_{y}, \ldots, \beta_{x}$ small). Also, assuming that the spacecraft main body angular velocity components referred to the principal axes of inertia $\left(\Omega_{\mathrm{x}}, \Omega_{\mathrm{y}}\right.$, and $\left.\Omega_{\mathrm{z}}\right)$ are very small, therefore neglecting their products.

Then the dynamics of the flexible spacecraft become (Lorenzo, 1975):

$$
\begin{aligned}
& \mathrm{I}_{x x} \Omega_{x}(t)+\mathrm{I}_{\mathrm{f}}\left(\ddot{a}_{\mathrm{x}}(\mathrm{t})+\beta_{\mathrm{x}}(\mathrm{t})\right)=\mathrm{T}_{\mathrm{x}}(\mathrm{t}) \\
& \mathrm{I}_{\mathrm{yy}} \Omega_{\mathrm{y}}(\mathrm{t})+\operatorname{ML}\left(\beta_{\mathrm{z}}(\mathrm{t})-\mathrm{a}_{\mathrm{z}}(\mathrm{t})\right)=\mathrm{T}_{\mathrm{y}}(\mathrm{t}) \\
& \mathrm{I}_{\mathrm{zz}} \Omega_{\mathrm{z}}(\mathrm{t})+\operatorname{ML}\left(\tilde{\mathrm{z}}_{\mathrm{y}}(\mathrm{t})-\beta_{\mathrm{y}}(\mathrm{t})\right)=\mathrm{T}_{\mathrm{z}}(\mathrm{t}) \\
& \tilde{a}_{x}(t)+\frac{G_{x}}{I_{f}} \dot{\alpha}_{x}(t)+\frac{K_{x}}{I_{f}} \alpha_{x}(t)=-\Omega_{x}(t) \\
& \beta_{x}(t)+\frac{C_{x}}{I_{f}} \beta_{x}(t)+\frac{K_{x}}{I_{f}} \beta_{x}(t)=-\Omega_{x}(t) \\
& \tilde{\alpha}_{y}(t)+\frac{K_{y}}{M} \dot{\alpha}_{y}(t)+\frac{K_{y}}{M} \alpha_{y}(t)=-\Omega_{z}(t) L \\
& \beta_{y}(t)+\frac{c_{y}}{M} \beta_{y}(t)+\frac{K_{y}}{M} \beta_{y}(t)=\Omega_{z}(t) L \\
& \vec{a}_{z}(t)+\frac{\sigma_{z}}{M} \dot{z}_{z}(t)+\frac{K_{z}}{M} \alpha_{z}(t)=\Omega_{y}(t) L \\
& \widehat{\beta}_{z}(t)+\frac{\underline{c}_{z}}{M} \beta_{z}(t)+\frac{K_{z}}{M} \beta_{z}(t)=-\Omega_{y}(t) L
\end{aligned}
$$

where $T_{x}(t), T_{y}(t)$. and $T_{z}(t)$ are the torques applied to the spacecraft main body. Moreover, if:

$$
\begin{gathered}
\mathrm{f}_{\mathrm{x}}=\alpha_{\mathrm{x}}+\beta_{\mathrm{x}} \\
\mathrm{f}_{\mathrm{y}}=\alpha_{\mathrm{y}}-\beta_{\mathrm{y}} \\
\mathrm{f}_{\mathrm{z}}=-\alpha_{\mathrm{z}}+\beta_{\mathrm{z}}
\end{gathered}
$$

the dynamics of the flexible spacecraft are described by the following decoupled set of equations (Lorenzo, 1975):

$$
\mathrm{I}_{\mathrm{x} x} \Omega_{\mathrm{x}}(\mathrm{t})+\mathrm{I}_{\mathrm{f}}^{\mathrm{Z}} \mathrm{f}(\mathrm{t})=\mathrm{T}_{\mathrm{x}}(\mathrm{t})
$$




$$
\begin{aligned}
\mathrm{I}_{\mathrm{f}} \mathrm{f}_{\mathrm{x}}(\mathrm{t})+\mathrm{C}_{\mathrm{x}} \mathrm{f}_{\mathrm{x}}(\mathrm{t})+\mathrm{K}_{\mathrm{x}} \mathrm{f}_{\mathrm{x}}(\mathrm{t})=-2 \mathrm{I}_{\mathrm{f}} \Omega_{\mathrm{x}}(\mathrm{t}) \\
\mathrm{I}_{\mathrm{y} y} \Omega_{\mathrm{y}}(\mathrm{t})+\mathrm{MLf}_{\mathrm{z}}(\mathrm{t})=\mathrm{T}_{\mathrm{y}}(\mathrm{t}) \\
\mathrm{Mf}_{\mathrm{z}}(\mathrm{t})+\mathrm{C}_{\mathrm{z}} \mathrm{f}_{\mathrm{z}}(\mathrm{t})+\mathrm{K}_{\mathrm{z}} \mathrm{f}_{\mathrm{z}}(\mathrm{t})=-2 \mathrm{ML} \Omega_{\mathrm{y}}(\mathrm{t}) \\
\mathrm{I}_{\mathrm{zz}} \Omega_{\mathrm{z}}(\mathrm{t})+\mathrm{ML} \mathrm{f}_{\mathrm{y}}(\mathrm{t})=\mathrm{T}_{\mathrm{z}}(\mathrm{t}) \\
\mathrm{Mf}_{\mathrm{y}}^{\mathrm{g}}(\mathrm{t})+\mathrm{C}_{\mathrm{y}} \mathrm{f}_{\mathrm{y}}(\mathrm{t})+\mathrm{K}_{\mathrm{y}} \mathrm{f}_{\mathrm{y}}(\mathrm{t})=-2 \mathrm{ML} \Omega_{\mathrm{z}}(\mathrm{t})
\end{aligned}
$$

\subsection{Kinematics}

The attitude motion of a spacecraft is basically represented by a set of two equations: (i) Euler's dynamic equation, which describes the time evolution of the angular velocity vector, and (ii) the kinematic equation, which relates the time derivatives of the orientation angles to the angular velocity vector. Several kinematic parameterizations exist to represent the orientation angles, including singular, three-parameter representations (e.g., the Euler angles, Gibbs vector) (Costic et al, 2000). Four-parameter attitude representations such as quaternions avoid the problem of singular points and have better numerical properties than more conventional three-parameter representations (Kristiansen et al, 2009).

The use of a quaternion $\left(\mathrm{q}_{\mathrm{o}}, \mathrm{q}_{\mathrm{x}}, \mathrm{q}_{\mathrm{y}}, \mathrm{q}_{\mathrm{z}}\right)^{\mathrm{T}}$ in describing the orientation of a rigid body lend themselves well to calculation with aid of an onboard computer since only products and no goniometric relations (which arises in using the Euler angles) exist in the formula. The quaternion equation yields (Wen \& Kruetz, 1991):

With

$$
\left[\begin{array}{l}
\dot{q}_{0} \\
\dot{q}_{\mathrm{x}} \\
\dot{q}_{\mathrm{y}} \\
\dot{q}_{\mathrm{z}}
\end{array}\right]=0.5\left[\begin{array}{cccc}
0 & -\Omega_{\mathrm{x}} & -\Omega_{\mathrm{y}} & -\Omega_{\mathrm{z}} \\
\Omega_{\mathrm{x}} & 0 & \Omega_{\mathrm{z}} & -\Omega_{\mathrm{y}} \\
\Omega_{\mathrm{y}} & -\Omega_{\mathrm{z}} & 0 & \Omega_{\mathrm{x}} \\
\Omega_{\mathrm{z}} & \Omega_{\mathrm{y}} & -\Omega_{\mathrm{x}} & 0
\end{array}\right]\left[\begin{array}{l}
\mathrm{q}_{0} \\
\mathrm{q}_{\mathrm{x}} \\
q_{\mathrm{y}} \\
\mathrm{q}_{\mathrm{z}}
\end{array}\right]
$$

$$
q_{0}^{2}+q_{x}^{2}+q_{y}^{2}+q_{2}^{2}=1
$$

Four variables $\mathrm{q}_{\mathrm{o}}, \mathrm{q}_{\mathrm{x}}, \mathrm{q}_{\mathrm{y}}$ and $\mathrm{q}_{\mathrm{z}}$, coupled by means of Equation (46), uniquely describe the orientation of the spacecraft in space.

\subsection{Reference model}

The angular velocity $\Omega(t)$ of the spacecraft is measured with gyros. Its orientation $q(t)$ is calculated via the quaternion (45). Consequently, the state of the spacecraft $(\boldsymbol{\Omega}$ and $\mathbf{q})$ is accurately known. In this work, a model reference adaptive controller is proposed to realize a fast, three axes slew about the Euler axis, even in the presence of parameter variations inside the spacecraft and internal (friction of the reaction wheel) and external disturbances. The reference model is used for realizing one single three axes slew. It calculates the trajectory in space from the present to the desired orientation. The spacecraft is forced to follow this trajectory so that it will perform a three axes slew as well and it will reach its desired attitude in space. The proposed reference model is selected to be a linearized, decoupled model of the spacecraft without disturbance and gyroscopic coupling; i.e. the reference model will exhibit an ideal trajectory. 
The proposed control signal of the reference model, $\mathrm{u}_{\mathrm{m}}(\mathrm{t})$, is derived from the corresponding quaternion $\mathrm{q}_{\mathrm{m}}(\mathrm{t})$ and the angular velocity $\Omega_{\mathrm{m}}(\mathrm{t})$ for each axis separately, namely:

$$
\mathrm{u}_{\mathrm{m}}(\mathrm{t})=-\mathrm{k}_{\mathrm{m} 1} \mathrm{q}_{\mathrm{m}}(\mathrm{t})-\mathrm{k}_{\mathrm{m} 2} \Omega_{\mathrm{m}}(\mathrm{t})
$$

where $k_{\mathrm{m} 1}$ and $\mathrm{k}_{\mathrm{m} 2}$ are constant feedback gains. This control strategy guarantees zero steadystate error in the model response. The reference model will always reach the desired attitude in space by one single three axes slew. Before a new slew can be made, a new reference frame has to be calculated, such that the required orientation will be the origin of this new reference frame. So, at the end of each slew $\mathrm{q}_{\mathrm{mx}}=\mathrm{q}_{\mathrm{my}}=\mathrm{q}_{\mathrm{mz}}=0$ and $\mathrm{q}_{\mathrm{mo}}=1$. In general, $\mathrm{q}_{\mathrm{mo}}$ will be large compared with $\mathrm{q}_{\mathrm{mx}}, \mathrm{q}_{\mathrm{my}}$, and $\mathrm{q}_{\mathrm{mz}}$. Therefore, the quaternion (45) can be linearized and decoupled. Taking the $x$-axis, for example, then:

$$
\dot{q}_{\mathrm{mx}}(\mathrm{t})=0.5 \Omega_{\mathrm{mx}}(\mathrm{t})
$$

This approximation, by which the model of one axis becomes linear and decoupled, allows the gains $\mathrm{k}_{\mathrm{m} 1 \mathrm{x}}$ and $\mathrm{k}_{\mathrm{m} 2 \mathrm{x}}$ to be calculated analytically. The authors in (Van Den Bosch et al., 1986) have chosen the undamped natural frequency $w_{n}$ and the relative damping ratio $\xi$ as design parameters, such that the feedback gains are calculated as follows:

$$
\mathrm{k}_{\mathrm{m} 1 \mathrm{x}}(\mathrm{t})=\frac{W_{n}^{2} I_{m x}}{\operatorname{sen}_{\operatorname{mx}}}
$$

and

$$
\mathrm{k}_{\mathrm{m} 2 \mathrm{x}}(\mathrm{t})=\frac{2 \mathrm{~W}_{\mathrm{n}} \mathrm{I}_{\operatorname{mx}}}{\operatorname{tmx}}
$$

where $I_{m x}$ is the moment of inertia of the model $x$-axis and $g_{m x}$ is the gain of the model reaction wheels. This idea is adopted in this work.

\subsection{Control with reaction wheels}

Reaction wheels are momentum exchange devices which provide reaction torque to a spacecraft and store angular momentum. When reaction wheels are used to provide momentum $\mathrm{H}$ with respect to the body axes, the torques exerted on the spacecraft are (Wie et al. 1985):

$$
\begin{gathered}
\mathrm{T}_{\mathrm{x}}(\mathrm{t})=-\hat{H}_{\mathrm{x}}(\mathrm{t}) \\
\mathrm{T}_{\mathrm{y}}(\mathrm{t})=-\hat{H}_{\mathrm{y}}(\mathrm{t})-\Omega_{\mathrm{z}}(\mathrm{t}) \mathrm{H}_{\mathrm{o}} \\
\mathrm{T}_{\mathrm{z}}(\mathrm{t})=-\hat{H}_{\mathrm{z}}(\mathrm{t})+\Omega_{\mathrm{y}}(\mathrm{t}) \mathrm{H}_{\mathrm{o}}
\end{gathered}
$$

Where $\mathrm{H}_{x}(\mathrm{t}), \mathrm{H}_{\mathrm{y}}(\mathrm{t})$, and $\mathrm{H}_{\mathrm{z}}(\mathrm{t})$ are the components of $\mathrm{H}$ along the body axes. $\mathrm{H}_{\mathrm{o}}$ is the nominal value of $H_{x}(t)$, the largest component of $H$. If equations (51) are substituted into Equations (44), the set of equations describing the dynamics of the flexible spacecraft may be written as (Lorenzo, 1975; Wie et al. 1985):

$$
\mathrm{I}_{x x} \Omega_{x}(t)+I_{f} \mathrm{f}_{x}(t)=-\bar{H}_{x}(t)
$$




$$
\begin{gathered}
I_{f}^{f} f_{x}(t)+C_{x} f_{x}(t)+K_{x} f_{x}(t)+2 I_{f} \Omega_{x}(t)=0 \\
I_{y y} \Omega_{y}(t)+H_{o} \Omega_{z}(t)+M L f_{z}(t)=-\hat{H}_{y}(t) \\
M f_{z}^{\prime}(t)+C_{z} f_{z}(t)+K_{z} f_{z}(t)+2 M L \Omega_{y}(t)=0 \\
I_{z z} \Omega_{z}(t)-H_{o} \Omega_{y}(t)+M L f_{y}(t)=-\hat{H}_{z}(t) \\
M f_{y}(t)+C_{y} f_{y}(t)+K_{y} f_{y}(t)+2 M L \Omega_{z}(t)=0
\end{gathered}
$$

The system is broken into two linear systems. The first (Equations (52)), describes the behavior around the $x$ axis only. The second (Equations (53)), describes the behavior of the coupled $\mathrm{y}$ and $\mathrm{z}$ axes.

For simplicity, the usual practice is to consider decoupled actuating torques (Lorenzo, 1975; Wie et al. 1985). This means that there are no interferences among the spacecraft axes due to the rotation of each reaction wheel, so that Equations (52) and (53) which represent the dynamics of the flexible spacecraft remain linear. But, practically, this is not true because each reaction wheel, rotating about one axis, will cause gyroscopic coupling among the other two axes.

In this work, the dynamics of flexible spacecraft is taken coupled and nonlinear. Although this will complicate the control algorithm but at the same time it will further enhance the performance of the attitude control system.

The complete set of equations used here to describe the flexible spacecraft is:

$$
\begin{aligned}
& \dot{q}_{\mathrm{o}}(\mathrm{t})=0.5\left(-\Omega_{\mathrm{x}}(\mathrm{t}) \mathrm{q}_{\mathrm{x}}(\mathrm{t})-\Omega_{\mathrm{y}}(\mathrm{t}) \mathrm{q}_{\mathrm{y}}(\mathrm{t})-\Omega_{\mathrm{z}}(\mathrm{t}) \mathrm{q}_{\mathrm{z}}(\mathrm{t})\right) \\
& \dot{q}_{x}(t)=0.5\left(+\Omega_{x}(t) q_{o}(t)+\Omega_{z}(t) q_{y}(t)-\Omega_{y}(t) q_{z}(t)\right) \\
& \dot{q}_{\mathrm{y}}(\mathrm{t})=0.5\left(+\Omega_{\mathrm{y}}(\mathrm{t}) \mathrm{q}_{\mathrm{o}}(\mathrm{t})-\Omega_{\mathrm{z}}(\mathrm{t}) \mathrm{q}_{\mathrm{x}}(\mathrm{t})+\Omega_{\mathrm{x}}(\mathrm{t}) \mathrm{q}_{\mathrm{z}}(\mathrm{t})\right) \\
& \dot{q}_{z}(t)=0.5\left(+\Omega_{z}(t) q_{o}(t)+\Omega_{y}(t) q_{x}(t)-\Omega_{x}(t) q_{y}(t)\right)
\end{aligned}
$$

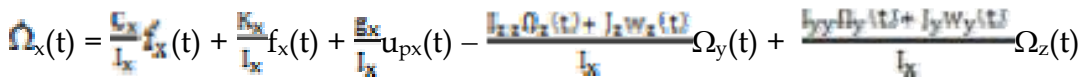

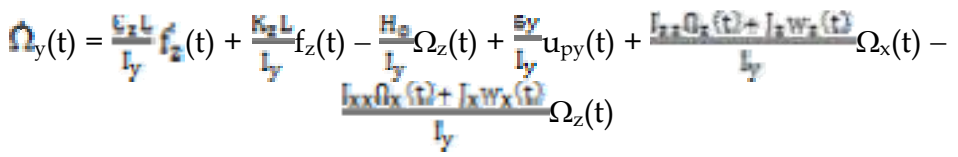

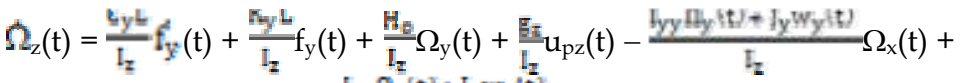

$$
\begin{aligned}
& \frac{D_{x \times O} \Omega_{x}(t)+I_{x} W_{x}(t)}{I_{z}} \Omega_{y}(t) \\
& f_{x}(t)=-\frac{C_{x} I_{x x}}{I_{f} I_{x}} f_{x}(t)-\frac{K_{x} I_{x x}}{I_{f} I_{x}} f_{x}(t)-2 \frac{E_{x}}{I_{x}} u_{p x}(t)+2 \frac{I_{z x} Q_{z}(t)+T_{z} W_{z}(t)}{I_{x}} \Omega_{y}(t) \\
& -2 \frac{\mathrm{L}_{y y} \Omega_{\mathrm{y}}[\mathrm{t}]+\mathrm{I}_{y} \mathrm{w}_{\mathrm{y}}[\mathrm{t}] \mathrm{f}}{\mathrm{I}_{\mathrm{x}}} \Omega_{\mathrm{z}}(\mathrm{t})
\end{aligned}
$$




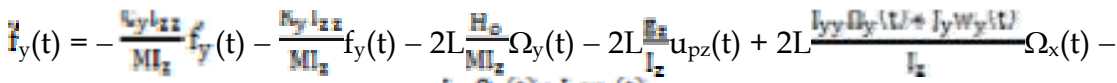

$$
\begin{aligned}
& 2 L \frac{{ }_{x x} \Omega_{x}(t)+I_{x} w_{x}(t)}{I_{z}} \Omega_{y}(t)
\end{aligned}
$$

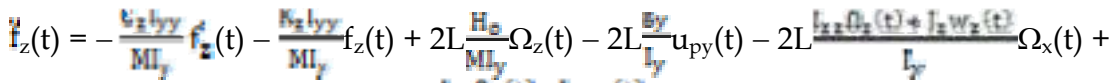

$$
\begin{aligned}
& 2 L \frac{\mathrm{Fxx}_{\mathrm{x}} \Omega_{\mathrm{x}}(\mathrm{t})+\mathrm{I}_{\mathrm{x}} w_{\mathrm{x}}(\mathrm{t})}{\mathrm{I}_{\mathrm{y}}} \Omega_{\mathrm{z}}(\mathrm{t})
\end{aligned}
$$

where $\mathrm{J}$ is the moment of inertia of each reaction wheel; $\mathrm{w}_{\mathrm{x}}, \mathrm{w}_{\mathrm{y}}$, and $\mathrm{w}_{\mathrm{z}}$ are the angular velocities of the reaction wheels; $g$ is the gain of each reaction wheel; and $u_{p x}, u_{p y}$ and $u_{p z}$ are the control signals for each axis.

Equations (54) to (57) represent the kinematics of the spacecraft. Equations (58) to (60) represent the dynamics of flexible spacecraft main body. While equations (61) to (63) represent the dynamics of the solar arrays.

The proposed model of the three axes of the reference model is given by:

$$
\begin{gathered}
q_{m}(t)=0.5 \Omega_{m}(t) \\
\hat{\Omega}_{m}(t)=-\frac{K_{m 1} E_{m}}{I_{m}} q_{m}(t)-\frac{K_{m_{2}} g_{m}}{I_{m}} \Omega_{m}(t)
\end{gathered}
$$

for each axis individually, i.e. linearized and decoupled.

In this work, a decentralized adaptive control strategy which uses a threefold single axis reference model is proposed for controlling the attitude of flexible spacecraft.

\section{Simulation results}

To test the decentralized minimal controller synthesis algorithm, the following data of a flexible satellite are simulated for a large-angle slew of $\left(0^{\circ}, 60^{\circ}, 60^{\circ}\right)$ (Lorenzo, 1975):

$\mathrm{I}_{\mathrm{x}}=250 \mathrm{kgm}^{2} ; \mathrm{I}_{\mathrm{y}}=1500 \mathrm{kgm}^{2} ; \mathrm{I}_{\mathrm{z}}=1800 \mathrm{kgm}^{2} ; \mathrm{I}_{\mathrm{f}}=25 \mathrm{kgm}^{2} ; \mathrm{C}_{\mathrm{x}}=1 \mathrm{kgm}^{2} \mathrm{rad} / \mathrm{s} ; \mathrm{C}_{\mathrm{y}}=1.75 \mathrm{~kg} / \mathrm{s} ;$ $\mathrm{C}_{\mathrm{z}}=1.75 \mathrm{~kg} / \mathrm{s} ; \mathrm{K}_{\mathrm{x}}=1 \mathrm{kgm}{ }^{2} \mathrm{rad} / \mathrm{s}^{2} ; \mathrm{K}_{\mathrm{y}}=2.8 \mathrm{~kg} / \mathrm{s}^{2} ; \mathrm{K}_{\mathrm{z}}=2.8 \mathrm{~kg} / \mathrm{s}^{2} ; \mathrm{L}=10 \mathrm{~m} ; \mathrm{M}=70 \mathrm{~kg} ; \mathrm{H}_{\mathrm{o}}=$ $100 \mathrm{Nms} ; \mathrm{J}=\mathrm{J}_{\mathrm{m}}=0.072 \mathrm{kgm}^{2} ; \mathrm{g}=\mathrm{g}_{\mathrm{m}}=0.08 \mathrm{Nm} / \mathrm{A} ; \boldsymbol{\Omega}(0)=[0,0,0]^{\mathrm{T}}(\mathrm{rad} / \mathrm{s}) ; \mathbf{w}(0)=[-70,10,-30]^{\mathrm{T}}$ $(\mathrm{rad} / \mathrm{s}) ; \xi=0.95 ; \mathrm{w}_{\mathrm{n}}=0.035 \mathrm{rad} / \mathrm{s}$.

Even with the high nonlinearity of the presented decentralized adaptive controller, the simulation results show that this controller is extremely efficient when it's implemented for maneuvering a flexible satellite. The angular displacement response is shown in figure (4). The problem of existence of oscillations in the transient response of the flexible satellite, which causes the excitation of the solar arrays, is usually encountered in the literature (Marchal, 1983; Van Den Bosch, 1986; Singh, 1988). But, in this work, due to the robustness of the presented adaptive algorithm this problem is avoided and the solar arrays exhibit only few oscillations during the maneuvering of the flexible satellite as shown in figure (5).

\section{Conclusion}

A model reference adaptive control methodology is presented by using hyperstability theory. The main contribution of this work effort lies in the use of decentralized minimal controller synthesis algorithm to guarantee the overall asymptotic stability and to highly enhance the robustness of the attitude control system of flexible spacecraft against disturbances. 


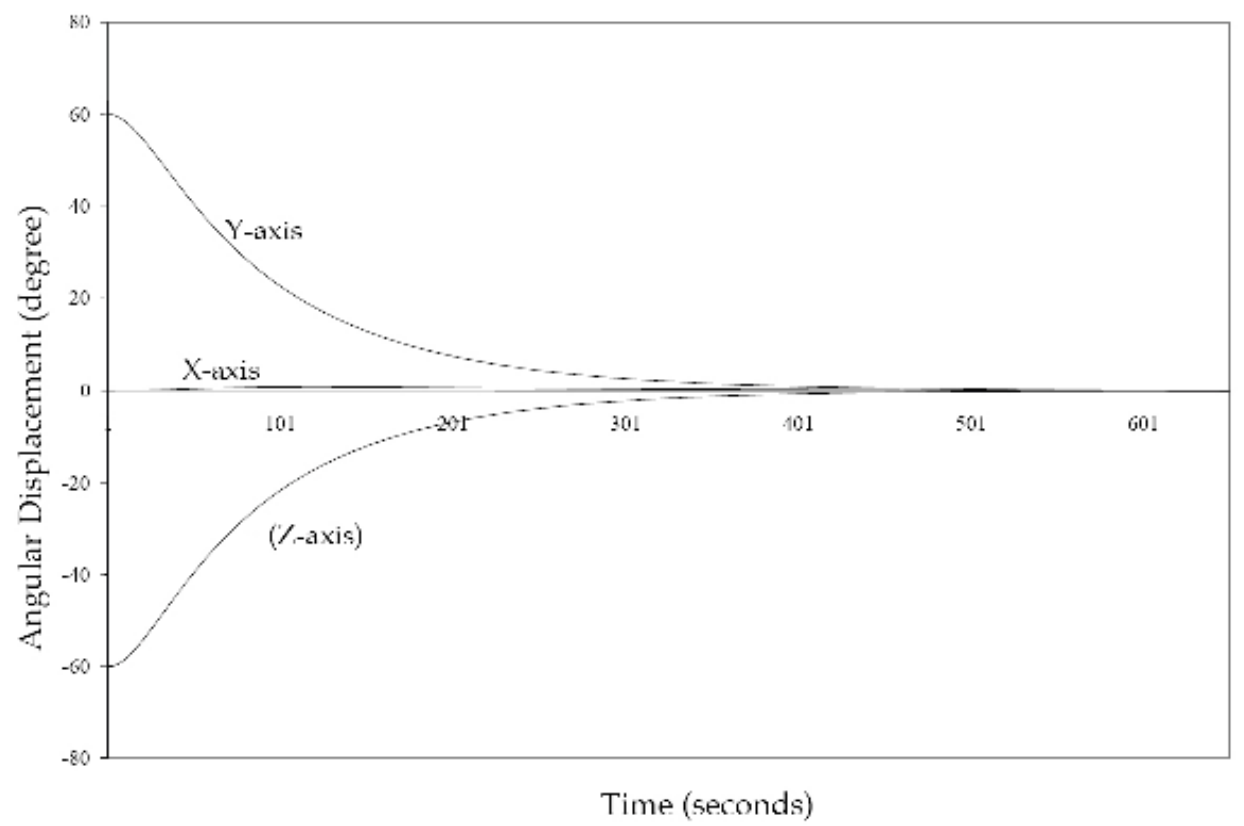

Fig. 4. Angular Displacement Response of Main Body

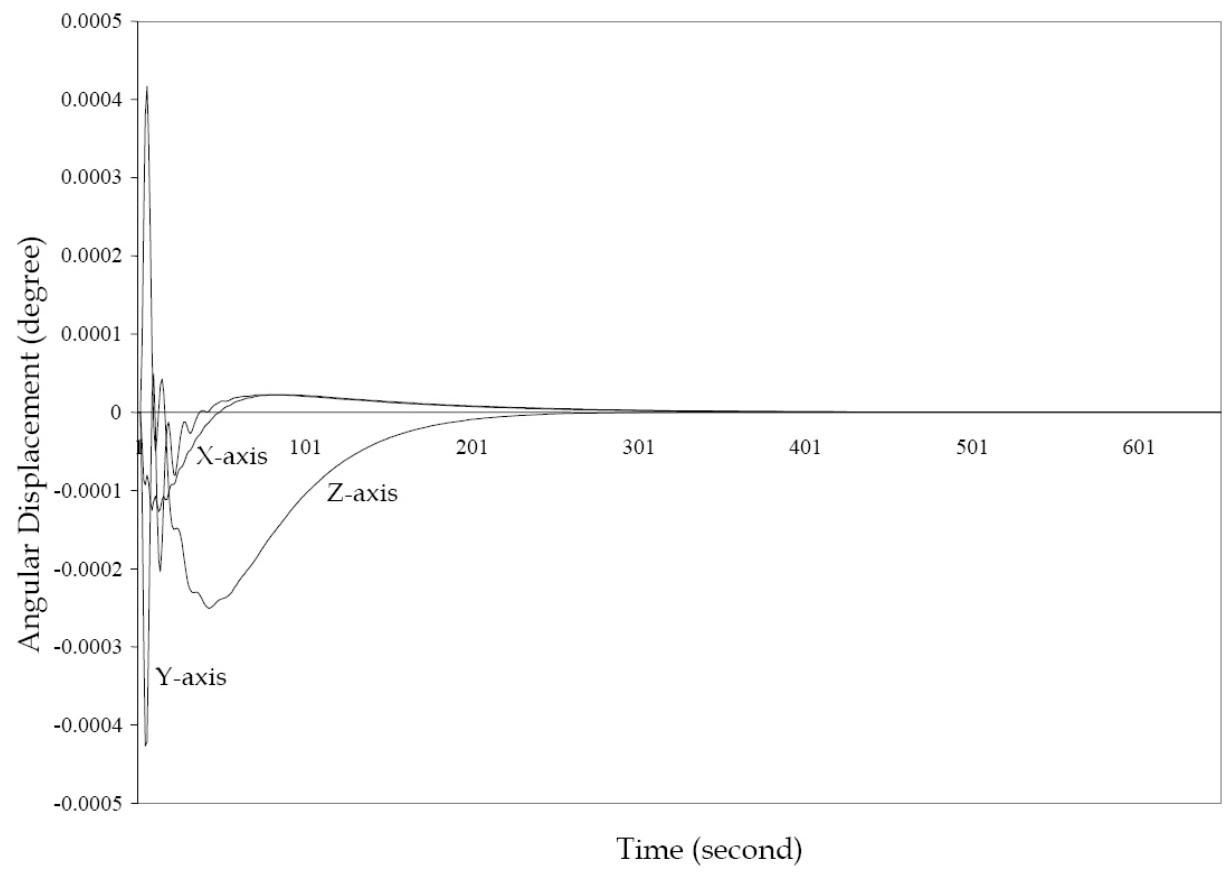

Fig. 5. Angular Displacement Response of Solar Array 
It is concluded that for a large-scale control system whose dynamics are coupled and nonlinear, the recommendation is to use the decentralized adaptive control schemes for controlling such system since they give better performance than that of centralized adaptive control schemes.

The dynamics of the main body of the flexible spacecraft are usually considered, in some literature, separately from that of the flexible arrays. In other literature, the torques exerted by the reaction wheels is taken decoupled for simplicity. In this work, the dynamics of the main body and the solar arrays are considered as coupled. Moreover, the reaction wheels' torques is taken coupled, too. This leads to the complexity of the attitude control system algorithm because the flexible spacecraft dynamics become highly coupled and nonlinear. Nevertheless, the performance of the attitude control system is highly enhanced.

The application of the decentralized minimal controller synthesis algorithm for the attitude control of flexible spacecraft gives excellent results concerning the behavior of the solar arrays during the maneuvering of the spacecraft.

\section{References}

Arif, T. (2008). Adaptive Control of Rigid Body Satellite, International Journal of Automation and Computing, Vol. 5, No. 3, pp. 296-306, ISSN: 1476-8186.

Benchoubane, H. \& Stoten, D. (1992). The Decentralized Minimal Controller Synthesis Algorithm, International Journal of Control, Vol. 56, No. 4, pp. 867-983, ISSN: 0020-7179.

Breakwell, J. (1981). Optimal Control Slewing of Flexible Spacecraft, Journal of Guidance and Control, Vol. 4, No. 4, pp. 472-479, ISSN 0731-5090.

Campbell, B. \& Lieven, N. (2002). Fault Tolerant Control Using Minimal Controller Synthesis for the X-38 Crew Return Vehicle. Proceedings of the $5^{\text {th }}$ ESA International Conference on Spacecraft Guidance, Navigation and Control Systems, pp. 185-190, ISBN: 92-9092-826-3, Italy, October 2002, Frascati.

Costic, B.; Dawson, D.; de Queiroz \& Kapila, V. (2000). A Quaternion-Based Adaptive Attitude Tracking Controller without Velocity Measurements, Proceedings of the 39th IEEE Conference on Decision and Control, Vol. 3, pp. 2424-2429, ISBN 0-7803-6638-7, Australia, December 2000, IEEE Press, Sydney.

Datta, A. (1993). Performance Improvement in Decentralized Adaptive Control: A Modified Reference Scheme, IEEE Transactions on Automatic Control, Vol. 38, No. 11, pp. 17171722, ISSN: 0018-9286.

Di Bernardo, M. \& Stoten, D. (2006). Minimal Controller Synthesis Adaptive Control of Nonlinear Systems: Utilizing the Properties of Chaos, Philosophical Transactions of the Royal Society A: Mathematical, Physical and Engineering Sciences, Vol. 364, No. 1846, pp. 2397-2415, ISSN: 1472-2962.

Isermann, R. (1992). Adaptive Control Systems, Prentice Hall, ISBN: 0131374560, New York, USA.

Joshi, S.; Maghami P. \& Kelkar, A. (1995). Design of Dynamic Dissipative Compensators for Flexible Space Structures, IEEE Trans. on Aerospace and Electronic Systems, Vol. 31, No. 4, pp. 1314-1323, ISSN: 0018-9251.

Kristiansen, R.; Nicklasson, J. \& Gravdahl, J. (2009). Satellite Attitude Control by Quaternion-Based Backstepping, IEEE Transactions on Control Systems Technology, Vol. 17, No. 1, pp. 227-232, ISSN: 1036-6536.

Landau, I. \& Courtiol, B. (1974). Survey of Model Reference Adaptive Techniques - Theory and Applications, Automatica, Vol. 10, No. 4, pp. 353-379, ISSN: 0005-1098. 
Landau, I. (1979). Adaptive Control: the Model Reference Approach, Marcel Dekker, ISBN: 0824765484, New York, USA.

Lorenzo, R.; Santinelli, A. \& Sciacovelli, D. (1975). Some Attitude Control Synthesis for Satellites with Flexible Appendages, Automatica, Vol. 11, pp. 161-170, ISSN: 00051098.

Luo, W.; Chu, Y. \& Ling, K. (2005). Inverse Optimal Adaptive Control for Attitude Tracking of Spacecraft, IEEE Transactions on Automatic Control, Vol. 50, No. 11, pp. 1639-1654, ISSN: 0018-9286.

Marchal, C. (1983). Minimum Horizontal Rotations, Optimal Control Applications \& Methods, Vol. 4, pp. 357-363, ISSN: 0143-2087.

Metzger, R. (1979). A Simple Criterium for Satellite with Flexible Appendages, Proceedings of the $8^{\text {th }}$ IFAC Symposium on Automatic Control in Space, pp. 63-69, ISBN: 0080244491, England, July 1979, Oxford.

Pande, K. \& Ventachalam, R. (1982). Optimal Solar Pressure Attitude Control of Spacecraft, Acta Astronautica, Vol. 9, No. 9, pp.533-545, ISSN: 0094-4765.

Singh, S. (1988). Flexible Spacecraft Maneuver: Inverse Attitude Control and Modal Stabilization, Acta Astronautica, Vol. 17, No. 1, pp. 1-9, ISSN: 0094-4765.

Skaar, S.; Tang L. \& Yalda, I. (1986). On-Off Attitude Control of Flexible Satellites, Journal of Guidance, Vol. 9, No. 4, pp. 507-510, ISSN: 0731-5090.

Spooner, T. \& Passino, K. (1996). Adaptive Control of a Class of Decentralized Nonlinear Systems, IEEE Transactions on Automatic Control, Vol. 41, No. 2, pp. 280-284, ISSN: 0018-9286.

Stoten, D. \& Benchoubane, H. (1990a). Empirical Studies of an MRAC Algorithm with Minimal Controller Synthesis, International Journal of Control, Vol. 51, No. 4, pp. 823849, ISSN: 0020-7179.

Stoten, D. \& Benchoubane, H. (1990b). Robustness of a Minimal Controller Synthesis Algorithm, International Journal of Control, Vol. 51, No. 4, pp. 851-861, ISSN: 00207179.

Stoten, D. \& Hodgson, S. (1992). The Application of the Minimal Control Synthesis Algorithm to the Hybrid Control of Class 1 Manipulator, International Journal of Control, Vol. 56, No. 3, pp. 499-513, ISSN: 0020-7179.

Van Den Bosch, P.; Jongkind, W. \& Swieten, A. (1986). Adaptive Attitude Control for LargeAngle Slew Maneuvers, Automatica, Vol. 22, No. 2, pp. 209-215, ISSN: 0005-1098.

Van Woerkom, P. (1985). Mathematical Models of Flexible Spacecraft Dynamics: A Survey of Order Reduction Approaches, Proceedings of the 10 th IFAC Symposium on Automatic Control in Space, pp. 127-135, France, June 1985, Toulouse.

Wagg, D. \& Stoten, D. (2001). Substructuring of Dynamical Systems via the Adaptive Minimal Controller Synthesis Algorithm, Earthquake Engineering \& Structural Dynamics, Vol. 30, No. 6, pp. 865-877, ISSN: 0098-8847.

Wen, J. \& Kreutz-Delgado, K. (1991). The Attitude Control Problem, IEEE Transactions on Automatic Control, Vol. 36, No. 10, pp. 1148-1161, ISSN: 0020-7179.

Wertz, J. (1980). Spacecraft Attitude Determination and Control, D. Reidel, ISBN: 9027712042, Boston, MA, USA.

Wie, B. \& Plescia, C. (1984). Attitude Stabilization of Flexible Spacecraft during Stationkeeping Maneuvers, Journal of Guidance, Vol. 7, No. 4, pp. 430-436, ISSN: 0731-5090.

Wie, B.; Lehner, J. \& Plescia, C. (1985). Roll/Yaw Control of a Flexible Spacecraft Using Skewed Bias Momentum Wheels, Journal of Guidance, Vol. 8, No. 4, pp. 447-453, ISSN: 0731-5090. 


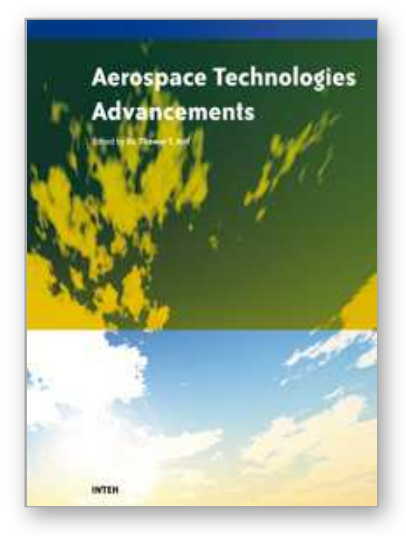

\author{
Aerospace Technologies Advancements \\ Edited by Thawar T. Arif
}

ISBN 978-953-7619-96-1

Hard cover, 492 pages

Publisher InTech

Published online 01, January, 2010

Published in print edition January, 2010

Space technology has become increasingly important after the great development and rapid progress in information and communication technology as well as the technology of space exploration. This book deals with the latest and most prominent research in space technology. The first part of the book (first six chapters) deals with the algorithms and software used in information processing, communications and control of spacecrafts. The second part (chapters 7 to 10) deals with the latest research on the space structures. The third part (chapters 11 to 14 ) deals with some of the latest applications in space. The fourth part (chapters 15 and 16) deals with small satellite technologies. The fifth part (chapters 17 to 20) deals with some of the latest applications in the field of aircrafts. The sixth part (chapters 21 to 25) outlines some recent research efforts in different subjects.

\title{
How to reference
}

In order to correctly reference this scholarly work, feel free to copy and paste the following:

Thawar Arif (2010). Spacecraft Attitude Control, Aerospace Technologies Advancements, Thawar T. Arif (Ed.), ISBN: 978-953-7619-96-1, InTech, Available from: http://www.intechopen.com/books/aerospace-technologiesadvancements/spacecraft-attitude-control

\section{INTECH}

open science | open minds

\section{InTech Europe}

University Campus STeP Ri

Slavka Krautzeka 83/A

51000 Rijeka, Croatia

Phone: +385 (51) 770447

Fax: +385 (51) 686166

www.intechopen.com

\section{InTech China}

Unit 405, Office Block, Hotel Equatorial Shanghai

No.65, Yan An Road (West), Shanghai, 200040, China 中国上海市延安西路65号上海国际贵都大饭店办公楼 405 单元

Phone: +86-21-62489820

Fax: $+86-21-62489821$ 
(C) 2010 The Author(s). Licensee IntechOpen. This chapter is distributed under the terms of the Creative Commons Attribution-NonCommercialShareAlike-3.0 License, which permits use, distribution and reproduction for non-commercial purposes, provided the original is properly cited and derivative works building on this content are distributed under the same license. 